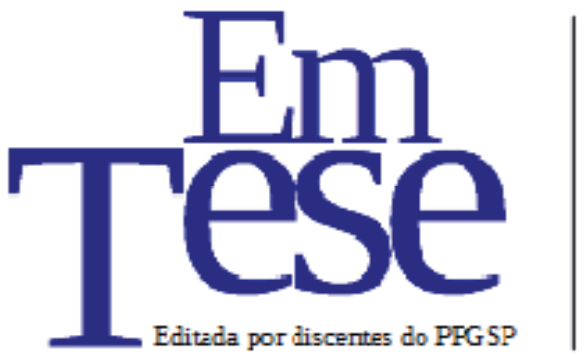

UFSC

PPG SP PROG RAMA DE

PÓS-GRADUAÇÃO EM

Sociologia

Política

\title{
A corrupção de um só: os efeitos de sentido do conceito de corrupção nas reportagens de capa da revista Veja
}

\author{
Raphael Sansonetti Valverde ${ }^{1}$ \\ Luísa Bonetti Scirea ${ }^{2}$
}

Resumo: O presente artigo analisa dos efeitos de sentido do conceito ou noções de corrupção presentes nas edições da revista Veja no primeiro semestre de 2015. Os sentidos das posições da Veja são analisados em relação aos quatro casos de corrupção considerados mais relevantes nesse período tendo como base a Análise do Discurso de linha francesa (ORLANDI, 2013) e as contribuições de Céli Pinto (2011) e Jessé Souza (2009). Considera-se que as noções de corrupção presentes na Veja nessas edições têm como base as ideologias do patrimonialismo e do personalismo compreendendo a corrupção como tendo origem no estado em contraposição ao mercado. Desta forma a responsabilidade da corrupção é personificada de forma reducionista em agentes políticos de apenas um partido político.

Palavras-chave: Corrupção. Veja. Patrimonialismo.

\section{The corruption of one: the effects of meaning of the concept of corruption in the} magazine covers cover Veja

\begin{abstract}
This article analyzes the meaning effects of the concept or notions of corruption in the Veja magazine editions in the first semester of 2015. The meanings of the Veja positions are analyzed in relation the four cases of corruption considered more relevant in this period having as base the french discourse analysis (ORLANDI, 2013) and the contributions of Céli Pinto (2011) and Jessé Souza (2009). It is considered that the notions of corruption in Veja in these editions have as base the ideologies of patrimonialism and personalism, comprising the corruption with an state origin in contraposition of the virtuous market. In this manner the responsibility of the corruption is personified in a reductionist way in politic agents of a single politic party.
\end{abstract}

Keywords: Corruption. Veja. Patrimonialism.

\footnotetext{
${ }^{1}$ Graduado em Psicologia pela Universidade Federal de Santa Catarina (UFSC) e mestrando em Sociologia Política na mesma universidade. E-mail: raphael.svalverde@gmail.com.

${ }^{2}$ Possui bacharelado e licenciatura em Ciências Sociais (UFSC). Mestranda em Sociologia Política na Universidade Federal de Santa Catarina (UFSC). E-mail: luisabonettis@gmail.com.
} 


\section{Introdução}

O tema e o conceito de corrupção estão em destaque no Brasil contemporâneo. A corrupção é mobilizada constantemente pelas diversas mídias, está nas redes sociais de usuários enfurecidos, aciona a memória política do senso comum do(a) brasileiro(a) e tornou-se fundamental no debate público dos últimos anos. Apesar da sua importância e de seu destaque, o tema apresenta significativa ausência nos estudos e artigos sociológicos no Brasil. São poucos os(as) cientistas sociais que abordam este tema árduo.

Jessé Souza (2009) aponta como as teses do patrimonialismo e do personalismo são ideias dominantes nas interpretações do Brasil, de forma a sustentar a crença de que a corrupção seria um "mal de origem” característico do país. Tais ideias se expressam em produções científicas da sociologia brasileira, tendo raízes em clássicos ensaístas como Sérgio Buarque e Gilberto Freyre, sendo atualizadas em contemporâneos como Roberto DaMatta, além de se expressarem nos valores do senso comum dos brasileiros de forma geral. Esta leitura do Brasil a partir de Sérgio Buarque e seu "homem cordial" caracteriza o povo brasileiro como tendencialmente corrupto, principalmente os sujeitos inseridos no estado, que deve ser mínimo e restrito, em contraposição ao mercado como espaço da virtude e de sujeitos virtuosos (SOUZA, 2009, p. 116-118).

Tal visão dual seria parte da ideologia liberal hegemônica e serviria para falsear a realidade brasileira e grandes problemas desta, como a grande desigualdade social no capitalismo brasileiro. A corrupção não deixa de ser um problema real, mas a partir de crenças do patrimonialismo como o "jeitinho brasileiro", ela seria analisada de forma essencialista ou personalista, sendo também analisada de maneira restritiva na esfera do estado, muitas vezes de forma espantalhesca. Essa oposição dual entre estado corrupto e mercado virtuoso seria um mito, uma vez que ambas as instituições e os sujeitos inseridos nelas têm características ambíguas e aspectos bons e ruins (SOUZA, 2009, p. 69-72). Tais teorias dominantes no Brasil e em parte da sociologia brasileira (Buarque e DaMatta, por exemplo) seriam expressões de um “culturalismo", que explicaria o Brasil como uma [...] singularidade social e cultural 'absoluta' [...] totalmente diferente dos países modernos de primeiro mundo (EUA e Europa, por ex.) e tendo características 
pré-modernas, associadas as características patrimonialistas e personalistas que dariam margem a corrupção no Brasil $^{3}$ (SOUZA, 2009, p.117-118).

Jessé Souza (2009) propõe uma interpretação alternativa ao "culturalismo", na qual o Brasil seria entendido como um país com características modernas, um estado centralizado e um mercado competitivo capitalista, assim como outros países modernos. O país também teria suas características específicas as quais não seriam características culturais únicas ou "essenciais" do Brasil e seu povo, como na leitura culturalista. Nessa leitura alternativa, apresentada por Jessé Souza, defende-se que são as sociedades e suas instituições que determinam os indivíduos e seus comportamentos, em contraposição a compreensão culturalista do brasileiro e, principalmente, do estado, como essencialmente patrimonialistas e corruptos (SOUZA, 2009, p. 104-106).

Celi Pinto (2011) também apresenta um interessante debate acerca da conceituação e dos usos do termo corrupção. Para a autora, este termo pode ser conceituado como "[...] uma forma de governar que encontra condições de emergência variadas, em diversificados cenários políticos, em tempos históricos diversos” (2011, p. 50). Com esta definição, ela busca se distanciar do moralismo que definiria a posição do senso comum acerca deste tema e, ao mesmo tempo, evidenciar que o Estado e a sociedade civil estão, em grande parte, associados no que tange ao fenômeno: não é possível existirem um Estado corrupto e uma sociedade civil honesta, ou um agente público corrupto sem que haja uma sociedade civil corruptora.

O conceito de corrupção, tal como definido por Pinto (2011), remete-se à ilegalidade ou à apropriação de bens públicos por entes privados. Assim, ele pode ser de dois tipos principais: a corrupção que mobiliza a iniciativa privada e o setor público, tal qual o pagamento de propina por parte de uma empresa privada para fechar contrato com algum ente público; e a corrupção que mobiliza apenas atores do setor público, ou o Estado, como os casos de enriquecimento ilícito pessoal ou do grupo familiar e político, nepotismo, etc. A mídia brasileira e o senso comum tenderiam a enfatizar, de acordo com Pinto (2011), os casos de corrupção intra-estatais.

\footnotetext{
${ }^{3}$ Jessé critica fortemente a leitura de Roberto DaMatta sobre países como EUA e Inglaterra, considerando sua visão romântica ao desconsiderar os diversos problemas destes países, inclusive quanto a seus problemas de corrupção. DaMatta consideraria a corrupção uma das particularidades de países menos desenvolvidos como o Brasil.
} 
Para além dessas duas definições, a autora também problematiza as ações ilícitas envolvendo prioritariamente entes privados. Esses casos, ainda que fujam ao sentido clássico de corrupção (que envolve ao menos um agente público), também causam prejuízos ao ente público, mesmo que de forma secundária como no caso da sonegação de impostos. Este artigo, assim, parte tanto da definição de Pinto (2011) acerca dos dois conceitos de corrupção (privado-público e intra-estatal), mas leva também em consideração a sua problematização pela existência mesma da corrupção entre agentes privados. Consideram-se também as críticas realizadas por Jessé Souza (2009) em relação à ideologia do patrimonialismo, o qual envolve as crenças essencialistas e personalistas da corrupção no Brasil, principalmente no que se refere à noção dual de estado corrupto e mercado virtuoso, crenças que dominam tanto parte da academia como do senso comum dos brasileiros.

O grande destaque de apenas um conceito de corrupção dado pelas principais mídias mobiliza efeitos de sentido específicos e pode trazer consequências importantes para o debate público, principalmente quando é realizado por veículos de comunicação que atingem um número considerável de pessoas. Tentando colaborar para a maior visibilidade e abordagem deste tema, o presente artigo visa compreender os efeitos de sentido vinculados ao conceito de corrupção na revista semanal de maior circulação no país, a revista Veja (editora Abril). A análise também será pautada pelo dispositivo teórico-analítico da Análise do Discurso de linha francesa em diálogo com as contribuições já citadas acerca do conceito de corrupção mobilizado por Pinto (2011) e Souza (2009).

Tendo essas bases teóricas, a análise se desenvolve a partir de duas dimensões: a primeira destaca a presença (ou ausência) e a frequência dos quatro casos de corrupção considerados mais significativos no cenário brasileiro nas 25 edições da Veja no primeiro semestre de 2015; e a segunda busca compreender o(s) efeito(s) de sentido(s) de corrupção que emergem das reportagens de capa que tratam destes casos de corrupção. Nosso corpus analítico tem como foco principal as "reportagens de capa" (de maior importância) da revista nos meses de janeiro a junho de 2015, tendo como dado de análise os casos recentes de corrupção no Brasil considerados mais significativos: Lava Jato; HSBC; Zelotes e FIFA. Serão levadas em consideração também a presença e a frequência das chamadas secundárias e respectivas reportagens. É importante destacar 
que não foram identificados outros casos de corrupção nas edições analisadas além dos quatro indicados acima.

\section{A análise do discurso e as condições de produção}

Para se iniciar a discussão, cabe situar um pouco melhor de onde partimos. A Análise do Discurso (AD) de linha francesa é frequentemente considerada uma área da linguística, apesar de possuir, desde sua origem, um caráter interdisciplinar. Sua emergência nos anos 1960 estava ligada ao diálogo estabelecido entre a Linguística, a Teoria Marxista e a Psicanálise, vinculando as três de tal forma que, conforme nos diz Eni Orlandi, autora referência em Análise do Discurso no Brasil, "partindo da ideia de que a materialidade específica da ideologia é o discurso e a materialidade específica do discurso é a língua, trabalha a relação língua-discurso-ideologia" (2013, p. 17). A pergunta que perpassa um trabalho que se propõe realizar uma análise do discurso é compreender como um objeto simbólico (texto, vídeo, foto, placa...) produz sentido(s).

Um dos pontos fundamentais desta concepção teórico-metodológico é conceber que o sentido não é uma propriedade literal das coisas, mas um efeito de linguagem: "os sentidos não estão só nas palavras, nos textos, mas na relação com a exterioridade, nas condições que eles são produzidos e que não dependem só das intenções dos sujeitos" (ORLANDI, 2013, p. 30). Isso indica que os sentidos do discurso podem ser múltiplos e muito diferentes dos que o pretendido pelo emissor do enunciado. Porém, se os sentidos podem ser vários, eles não podem ser qualquer um, isso porque

o dizer não é propriedade particular. As palavras não são só nossas. Elas significam pela história e pela língua. O que é dito em outro lugar também significa nas "nossas" palavras. O sujeito diz, pensa que sabe o que diz, mas não tem acesso ou controle sobre o modo pelo qual os sentidos se constituem nele (ORLANDI, 2013, p. 32).

Percebemos, então, que, para a $\mathrm{AD}$ de linha francesa, todo dizer é determinado tanto pelo interdiscurso (o já dito, a memória discursiva) como pelo intradiscurso (a formulação, enunciação). Apesar disso, a memória discursiva é afetada pelo esquecimento, conforme nos apontou Michel Pêcheux (apud ORLANDI, 2013) e, 
assim, o sujeito acredita serem suas as palavras que fala e ser ele quem controla o sentido do que diz.

Assim, para compreender os sentidos que emergem das reportagens vinculadas à Veja, é necessário evidenciar suas condições de produção e enunciação, a ligação da revista com o processo político institucional do país e conhecer quais eram os casos de corrupção que vieram a público nos primeiros seis meses de 2015, período em que analisamos as reportagens da revista.

A Veja é a revista de maior circulação no Brasil há décadas, pertence à editora Abril e foi fundada em 1968 por Roberto Cívita (dono) e Mino Carta (editor). Ela é uma revista semanal de informação, abordando temas variados, como política, economia, cultura. Ao longo de sua existência, sobretudo nos anos 2000, ela foi assumindo um caráter mais conservador e de "direita". Até o primeiro semestre de 2015, a Veja possuía em seu quadro de colunistas pessoas como Reinaldo Azevedo, conhecido pensador "conservador" brasileiro e Rodrigo Constantino, "liberal" declarado e presidente do Instituto Liberal do Rio de Janeiro. Inúmeros são os processos judiciais que a revista tem sido alvo. Estes são causados, em grande medida, pela "flexibilização" dos compromissos éticos jornalísticos que a revista apresenta, promovendo distorções em entrevistas e textos de suas fontes, tal como no caso da publicação de um trecho do texto do antropólogo brasileiro internacionalmente conhecido, Eduardo Viveiros de Castro $^{4}$ (COUTINHO; PAULIN; MEDEIROS, 2001). Já foi apontada em outra situação também a relação da Veja com lobistas ${ }^{5}$ (RIBEIRO, 2001).

Um artigo recente investiga a relação da revista com o tema da corrupção. Bruno Araújo e Thais Jorge (2015) abordam duas edições da revista Veja e Carta Capital, ambas do segundo semestre de 2005 e referentes ao caso do Mensalão, ou seja, os autores enfocam a relação da revista com o tema no início do mandato presidencial de Lula, primeira experiência do PT na presidência. Araújo e Jorge (2015) apontam que a revista Veja se volta para uma compreensão reducionista, legalista e personificada do

\footnotetext{
${ }^{4} \mathrm{O}$ caso ocorreu na reportagem "A farra da antropologia oportunista", publicado na edição 2163 da Veja de 05/05/2010. (COUTINHO; PAULIN; MEDEIROS, 2001). A distorção da argumentação do antropólogo mobilizou os movimentos indígenas e gerou nota de repúdio da Associação Brasileira de Antropologia (ABA), além de um processo do antropólogo contra a revista. Mais informações disponíveis no site da Associação nacional de pós graduação, disponível em: <http://www.anpg.org.br/?p=1916.>.

${ }^{5}$ Em 2001, o caso do lobista Alexandre Paes Santos foi divulgado na própria revista, sem que divulgassem o nome de uma editora da Veja que constava na agenda do lobista. Após um tempo, a ligação entre ambos veio a público e a editora foi demitida (RIBEIRO, 2001).
} 
fenômeno, acarretando num "reducionismo do debate e a validação tácita da estrutura social em que a corrupção se manifesta".

Para se compreender os efeitos de sentido da cobertura da revista Veja acerca dos casos de corrupção que vieram a público no Brasil recentemente, é relevante levar em consideração as condições de enunciação destas reportagens. A atuação da revista Veja de antecipar sua circulação justamente na edição em que a reportagem de capa declarava enfaticamente que Lula e Dilma sabiam do caso Lava Jato evidencia a importância da ação midiática nas eleições presidenciais como na continuidade do PT na presidência do Brasil para a produção de sentido sobres estes casos.

Além disso, os grandes eventos da Copa das Confederações e Copa do Mundo; as jornadas de Junho de 2013; os inúmeros casos de ódio e racismo direcionados aos (às) nordestinos(as), identificados como os principais eleitores de Lula e Dilma, manifestado por usuários(as) de redes sociais no Brasil; os casos de agressões a apoiadores(as) da presidenta reeleita; o desempenho econômico brasileiro abaixo do esperado, situação que se arrastava deste o primeiro mandato de Dilma; e a "crise política" que se desenhava no país a partir de 2013 também são dados relevantes para compreender aonde se inscrevia o discurso da revista Veja acerca do conceito de corrupção.

Os quatro casos de corrupção selecionados como dados para a análise aparecem com formas e amplitudes variadas na revista, sendo que também são os casos mais recentes a tornarem-se públicos no Brasil no período de produção deste artigo ${ }^{6}$. Eles expressam os diferentes tipos de corrupção trabalhados por Céli Pinto (2011) - Intraestado e Privado-Pública -, além de uma terceira forma apenas mencionada pela autora, a corrupção numa relação entre entes privados (PINTO, 2011, p. 54). Retomamos, a seguir, um pouco sobre o histórico de cada um desses casos e seus respectivos tipos de corrupção conforme a autora.

A chamada "operação Lava-Jato" 7 , desenvolvida pela Polícia Federal (PF) foi publicizada no dia 17 de março de 2014. A investigação vinha sendo realizada a partir

\footnotetext{
${ }^{6}$ O presente artigo foi escrito em julho/agosto de 2015, sendo revisado para publicação entre fevereiro e agosto de 2016. Vale lembrar que o caso Lava Jato se inicia em 17 de julho de 2014, sendo selecionado para a análise por ser um dos últimos casos de corrupção publicizados no Brasil e ter tido diversos desdobramentos, continuado na mídia brasileira até o presente momento.

${ }^{7}$ Entre janeiro e junho de 2015 a operação Lava-Jato contava com 14 fases de investigação, assim, destaca-se que a presente pesquisa enfoca apenas os dados disponíveis na época da produção do artigo entre janeiro e junho de 2015, em especial a partir da cobertura da Veja.
} 
de uma denúncia feita ainda em 2008. A operação tem o objetivo de investigar um grande esquema de lavagem de dinheiro, estimado em cerca de 10 bilhões de reais, sendo considerado pela PF um dos maiores casos de investigação sobre corrupção do país $^{8}$. Os envolvidos no esquema de corrupção compunham um conjunto de agentes tanto da esfera pública, políticos e funcionários da Petrobras ${ }^{9}$, como da esfera privada, empresários e empreiteiras.

As investigações da operação Lava-Jato apontavam para diversos tipos de crimes: lavagem de dinheiro, formação de organização criminosa, crimes contra o sistema financeiro nacional e falsidade ideológica. Dezenas de envolvidos foram presos, dentre estes Paulo Roberto da Costa, ex-diretor da Petrobras e o delator Alberto Youssef, doleiro do esquema. As investigações ainda estão em andamento e, até agosto de 2016, a operação Lava-jato já teve 33 diferentes fases. É relevante destacar a diversidade de siglas de partidos e o número de políticos citados nos inquéritos na época de produção deste artigo: 31 do PP, oito do PT, sete do PMDB, três do PSDB, um do PTB, um do PSD, entre outros.

Outro grande esquema de corrupção foi publicizado no início de fevereiro de 2015, principalmente por meio de jornais europeus como o The Guardian e o Le Monde que divulgaram documentos secretos da filial suíça do banco inglês HSBC. As informações tiveram como fonte inicial o ICIJ (International Consortium of Investigative Journalists), que repassou os dados a diversos jornais do mundo com base na denúncia de um ex-funcionário do HSBC. Tais documentos apontavam que cerca de 106 mil clientes, entre estes grandes empresários, políticos, pessoas famosas e até mesmo traficantes de drogas e armas, estariam envolvidos no esquema de corrupção. Em sua maioria, os agentes envolvidos eram do setor privado (o banco e seus clientes), sendo acusados principalmente dos crimes de lavagem de dinheiro e sonegação de impostos. As movimentações financeiras seriam realizadas por meio de contas secretas, alcançando o valor de 120 bilhões de dólares (334 bilhões de reais) desde 1988 até 2007, trazendo enorme prejuízo aos cofres públicos. Entre os envolvidos no caso HSBC estão cerca de 6606 contas de cidadãos brasileiros, colocando o Brasil como o quarto

\footnotetext{
${ }^{8}$ Informações disponíveis em: lavajato.mpf.mp.br.

${ }^{9}$ A Petrobras, Petróleo Brasileiro S.A, se caracteriza como uma empresa estatal de capital aberto e misto, tendo como maior acionista o Governo Brasileiro, além de acionistas privados.
} 
país com maior número de contas envolvidos no caso. Dentre as investigadas estão as de empresários dos grupos Safra e grupo Globo e até mesmo alguns envolvidos no caso Lava-Jato. Foi iniciada pelo Senado Federal brasileiro uma investigação sobre o caso, intitulada CPI do HSBC, conhecida também como "Suiçalão"10.

Outro caso de corrupção no Brasil, na amostra considerada, é da operação Zelotes, deflagrada pela PF em 26 de março de 2015. A operação Zelotes ${ }^{11}$ tinha o objetivo de realizar uma investigação sobre um esquema de corrupção envolvendo a Receita Federal, mais especificamente o CARF (Conselho de Administração de Recursos Fiscais), órgão da receita federal responsável por julgar os recursos administrativos relativos a autuações de empresas e pessoas físicas que sonegaram o físco ou a previdência $^{12}$.

O CARF é composto tanto de servidores públicos como de indicados de confederações e entidades de classe, ou seja, dos contribuintes da sociedade civil. A principal acusação ${ }^{13}$ movida ao CARF é que alguns conselheiros dessa entidade influenciaram os julgamentos e a tramitação de processos a favor de certas empresas mediante recebimento de dinheiro. O montante do prejuízo ao patrimônio público é estimado em cerca de 19 bilhões de reais, praticamente o dobro do inquérito da LavaJato. Entre os elementos envolvidos na investigação operação Zelotes estão tanto agentes públicos e privados relacionados ao CARF, assim como os agentes privados das grandes empresas beneficiárias do esquema, como Gerdau, RBS, Boston Negócios, Banco Santander, Banco Safra ou agentes políticos, como possivelmente políticos do PP (Partido Progressista).

\footnotetext{
10 Informações disponíveis em: http://www.cartacapital.com.br/economia/entenda-o-caso-dosvazamentos-do-hsbc-7392.html; http://www.icij.org e http://www12.senado.leg.br/noticias/senadoagora/2015/03/24/cpi-do-hsbc.

11 Informações disponíveis em: http://www.cartacapital.com.br/blogs/parlatorio/zelotes-gerdau-e-rbsafiliada-da-globo-sao-principais-alvos-diz-jornal-7182.html http://www1.folha.uol.com.br/mercado/2015/04/1611246-entenda-a-operacao-zelotes-da-policiafederal.shtml.

12 Destaca-se que a operação Zelotes, assim como a Lava-Jato, se desenvolveu em fases, estando ainda em andamento, sendo que no período de produção deste artigo apenas a primeira fase havia sido deflagrada. Em maio de 2016, a operação se encontrava em sua $7^{\mathrm{a}}$ fase.

${ }^{13}$ Informações disponíveis http://www.bbc.com/portuguese/noticias/2015/04/150414_carf_corrupcao_ms_rb.

em:
} 
Por último, em 27 de maio de 2015, o FBI (Federal Bureau of Investigation) indiciou nove diretores da FIFA ${ }^{14}$ sob a acusação de lavagem de dinheiro, fraude, extorsão, além da suspeita de terem recebido cerca de US\$ 150 milhões em suborno ${ }^{15}$. Esses processos ilegais ${ }^{16}$ realizados pelos diretores da FIFA tinham diversas facetas, desde a manipulação no processo de venda dos direitos de emissão/transmissão dos jogos da FIFA e na contratação de empresas que forneciam material esportivo para times, até a compra de votos na escolha das sedes da Copa do Mundo e nas eleições para presidência da própria FIFA. No caso FIFA, há majoritariamente relação de corrupção entre agentes privados - não que se excluam possíveis expressões desse caso atrelado a órgãos públicos dos países em que a entidade atua.

\section{Os efeitos de sentido(s) da corrupção}

Foram analisadas reportagens de capa de 25 edições impressas da revista Veja entre os meses de Janeiro a Junho de 2015. Como uma primeira dimensão analítica, foi considerada a presença ou ausência de reportagens sobre os quatro casos de corrupção mais recentes e de repercussão pública no Brasil (Lava Jato, HSBC, Zelotes e FIFA), assim como a frequência com que estes apareceram ao longo destes seis meses. As menções aos grupos particulares ou pessoas relacionadas a um dos quatro casos de corrupção foram categorizadas como menção a um dos "casos-chave" (Lava Jato, HSBC, Zelotes e FIFA).

$\mathrm{Na}$ tabela 1 podemos visualizar a intensidade da cobertura de cada caso na amostra de edições selecionadas dentro de três categorias, as reportagens de capa

\footnotetext{
${ }^{14}$ A Federação Internacional de Futebol - FIFA se caracteriza como a maior associação internacional relacionada ao Futebol, dirigindo diferentes modalidades do esporte. Ela foi fundada em 1904 e é governada por leis Suíças, sendo sua sede localizada em Zurique. Têm filiação com o Comitê Olímpico Internacional e dirige diversas confederações continentais que organizam seus respectivos campeonatos. Mais informações disponíveis em: http://www.fifa.com/.

15 Informações disponíveis em http://www.theguardian.com/football/2015/may/27/several-top-fifaofficials-arrested.

16 Informações disponíveis em: http://www.justice.gov/opa/pr/nine-fifa-officials-and-five-corporateexecutives-indicted-racketeering-conspiracy-and e http://g1.globo.com/mundo/noticia/2015/05/entendaacusacoes-de-corrupcao-fifa.html.
} 
(chamada principal), as reportagens secundárias que aparecem na capa (chamadas secundárias) e as reportagens sem chamada na capa (notícias secundárias).

Tabela 1 - Presença dos casos de corrupção nas reportagens de capa da revista Veja distribuídos por semana e mês entre Janeiro e Junho de 2015.

\begin{tabular}{|c|c|c|c|c|c|c|}
\hline \multicolumn{2}{|c|}{$\begin{array}{c}\text { CASOS DE } \\
\text { CORRUPÇÃO }\end{array}$} & HSBC & Lava - Jato & Zelotes & FIFA & Observações \\
\hline \multirow{4}{*}{ Janeiro } & $1^{\mathrm{a}}$ Semana & & & & & $\begin{array}{c}\text { A operação } \\
\text { Lava jato teve } \\
\text { início em } 17 \\
\text { de março de } \\
2014 .\end{array}$ \\
\hline & $2^{\text {a }}$ Semana & & $\begin{array}{l}\text { Chamada } \\
\text { secundária }\end{array}$ & & & \\
\hline & $3^{\text {a }}$ Semana & & $\begin{array}{c}\text { Notícia } \\
\text { secundária }\end{array}$ & & & \\
\hline & $4^{\mathrm{a}}$ Semana & & $\begin{array}{c}\text { Chamada } \\
\text { secundária. }\end{array}$ & & & \\
\hline \multirow{4}{*}{ Fevereiro } & $1^{\text {a }}$ Semana & & $\begin{array}{l}\text { Chamada } \\
\text { principal }\end{array}$ & & & $\begin{array}{l}\text { Dia } 8 \text { - Início } \\
\text { do caso HSBC }\end{array}$ \\
\hline & $2^{\mathrm{a}}$ Semana & & $\begin{array}{l}\text { Chamada } \\
\text { principal }\end{array}$ & & & \\
\hline & $3^{\text {a }}$ Semana & & $\begin{array}{l}\text { Chamada } \\
\text { principal }\end{array}$ & & & \\
\hline & $4^{\mathrm{a}}$ Semana & $\begin{array}{c}\text { Notícia } \\
\text { secundária }\end{array}$ & $\begin{array}{l}\text { Chamada } \\
\text { principal }\end{array}$ & & & $\begin{array}{l}\text { Notícia do } \\
\text { HSBC no } \\
\text { bloco de } \\
\text { economia. }\end{array}$ \\
\hline \multirow{4}{*}{ Março } & $1^{\mathrm{a}}$ Semana & & $\begin{array}{l}\text { Chamada } \\
\text { principal }\end{array}$ & & & $\begin{array}{c}\text { Reportagem } \\
\text { sobre quebra } \\
\text { de confiança } \\
\text { do governo e } \\
\text { da economia, } \\
\text { citando a } \\
\text { Petrobras na } \\
\text { capa. }\end{array}$ \\
\hline & $2^{\mathrm{a}}$ Semana & & $\begin{array}{l}\text { Chamada } \\
\text { principal }\end{array}$ & & & $\begin{array}{c}\text { Várias } \\
\text { reportagens } \\
\text { sobre a lava- } \\
\text { jato. }\end{array}$ \\
\hline & $3^{\text {a }}$ Semana & & $\begin{array}{c}\text { Notícia } \\
\text { secundária }\end{array}$ & & & \\
\hline & $4^{a}$ Semana & & $\begin{array}{l}\text { Notícia } \\
\text { secundária }\end{array}$ & & & $\begin{array}{c}\text { Dia } 26 \text { - Início } \\
\text { da Operação } \\
\text { Zelotes }\end{array}$ \\
\hline
\end{tabular}




\begin{tabular}{|c|c|c|c|c|c|c|}
\hline \multirow{5}{*}{ Abril } & $1^{\text {a }}$ Semana & $\begin{array}{c}\text { Notícia } \\
\text { secundária }\end{array}$ & $\begin{array}{l}\text { Chamada } \\
\text { secundária. }\end{array}$ & & & $\begin{array}{c}\text { Reportagem } \\
\text { enfoca como o } \\
\text { governo usa a } \\
\text { lista do HSBC } \\
\text { para } \\
\text { constranger } \\
\text { adversários. }\end{array}$ \\
\hline & $2^{\mathrm{a}}$ Semana & & $\begin{array}{l}\text { Chamada } \\
\text { secundária. }\end{array}$ & & & $\begin{array}{l}\text { Lava-jato: fala } \\
\text { de táticas para } \\
\text { esvaziamento } \\
\text { do escândalo. }\end{array}$ \\
\hline & $3^{a}$ Semana & & & $\begin{array}{c}\text { Notícia } \\
\text { secundária. }\end{array}$ & & $\begin{array}{c}\text { Não cita o } \\
\text { termo } \\
\text { “operação } \\
\text { Zelotes” nem } \\
\text { na chamada } \\
\text { nem no título } \\
\text { da reportagem. } \\
\text { O enfoque da } \\
\text { corrupção na } \\
\text { reportagem é } \\
\text { em Dilma. } \\
\end{array}$ \\
\hline & $4^{\mathrm{a}}$ Semana & & $\begin{array}{l}\text { Chamada } \\
\text { principal }\end{array}$ & & & \\
\hline & $5^{\mathrm{a}}$ Semana & & $\begin{array}{l}\text { Chamada } \\
\text { principal e } \\
\text { Notícia } \\
\text { Secundária. }\end{array}$ & & & $\begin{array}{l}\text { A reportagem } \\
\text { secundária na } \\
\text { seção de } \\
\text { economia } \\
\text { aponta } \\
\text { prejuízo de } 20 \\
\text { bilhões na } \\
\text { Petrobras em } \\
2014 .\end{array}$ \\
\hline \multirow{4}{*}{ Maio } & $1^{a}$ Semana & & $\begin{array}{l}\text { Chamada } \\
\text { principal }\end{array}$ & & & \\
\hline & $2^{a}$ Semana & & & & & \\
\hline & $3^{a}$ Semana & & $\begin{array}{l}\text { Chamada } \\
\text { principal }\end{array}$ & & & \\
\hline & $4^{\mathrm{a}}$ Semana & & $\begin{array}{c}\text { Notícia } \\
\text { secundária }\end{array}$ & & & $\begin{array}{l}\text { Dia } 27 \text { - Início } \\
\text { do caso FIFA }\end{array}$ \\
\hline \multirow{4}{*}{ Junho } & $1^{\mathrm{a}}$ Semana & & $\begin{array}{c}\text { Notícia } \\
\text { secundária }\end{array}$ & & $\begin{array}{l}\text { Chamada } \\
\text { principal }\end{array}$ & \\
\hline & $2^{a}$ Semana & & $\begin{array}{c}\text { Notícia } \\
\text { secundária }\end{array}$ & & $\begin{array}{l}\text { Chamada } \\
\text { secundária }\end{array}$ & \\
\hline & $3^{a}$ Semana & $\begin{array}{c}\text { Notícia } \\
\text { secundária }\end{array}$ & $\begin{array}{c}\text { Notícia } \\
\text { secundária }\end{array}$ & & & \\
\hline & $4^{\mathrm{a}}$ Semana & & $\begin{array}{l}\text { Chamada } \\
\text { principal }\end{array}$ & & & \\
\hline
\end{tabular}


Percebe-se, a partir da Tabela 1, a grande intensidade da cobertura da revista Veja sobre o caso Lava-Jato. Este foi deflagrado em 17 de Março de 2014. As edições da revista analisadas neste artigo, nossa amostra, são referentes ao período de Janeiro a Junho de 2015. Sendo assim, o total de edições da revista Veja em que o caso poderia aparecer seriam 25 edições. Como o caso foi citado em 22 edições, tem presença em $88 \%$ das edições possíveis. Raciocínio semelhante foi empregado para calcular as porcentagens da intensidade da cobertura dos casos HSBC, Zelotes e FIFA. O caso HSBC está presente em três das 20 edições analisadas que poderiam cobrir tal investigação, cerca de $15 \%$ de cobertura. O caso Zelotes está presente em apenas uma das 13 edições analisadas que poderiam cobrir tal investigação, cerca de 8\%. Já o caso FIFA está presente em duas das quatro edições que poderiam cobrir tal investigação, cerca de $50 \%$ de cobertura. Destaca-se, entretanto, que o período avaliado referente ao caso FIFA é muito breve, limitando-se a junho de 2015, último mês na amostra semestral aqui considerada.

$\mathrm{Na}$ tabela 2 apresentamos a quantidade dos casos-chave nas reportagens de capa da revista Veja (chamada principal), como também os casos de chamadas secundárias (reportagens secundárias na capa) e de notícias secundárias (sem chamadas na capa).

Tabela 2 - Quantidade dos casos-chave de corrupção nas reportagens de capa e nos índices das edições da revista Veja entre Janeiro e Junho de 2015.

\begin{tabular}{|c|c|c|c|c|}
\hline Casos & HSBC & Lava-Jato & Zelotes & FIFA \\
\hline $\begin{array}{c}\text { Chamada } \\
\text { Principal }\end{array}$ & - & 11 & - & 1 \\
\hline $\begin{array}{c}\text { Chamada } \\
\text { secundária }\end{array}$ & - & 4 & - & 1 \\
\hline $\begin{array}{c}\text { Notícia } \\
\text { secundária }\end{array}$ & 3 & 7 & 1 & - \\
\hline Total & 3 & 22 & 1 & 2 \\
\hline
\end{tabular}


Nas 25 edições da Veja analisadas, o caso HSBC aparece apenas três vezes e em todas como notícias secundárias (nenhuma menção na capa); a operação Zelotes aparece sendo citada apenas uma vez em uma notícia secundária, sendo o foco da reportagem o suposto envolvimento de Dilma com uma suspeita no caso Zelotes; o caso da FIFA aparece em uma chamada principal e em uma secundária; por último, a operação LavaJato aparece em 11 chamadas principais, quatro chamadas secundárias e sete notícias secundárias.

Nessa segunda dimensão analítica, a partir da leitura e análise das 12 reportagens de capa da Veja, destacamos agora alguns pontos que nos ajudam a compreender os efeitos de sentido que a cobertura da revista sobre os casos recentes de corrupção produz sobre o tema. Das 12 reportagens de capa analisadas neste artigo, 11 eram sobre o caso Lava-Jato, uma era sobre o caso FIFA e não havia reportagens de capa referentes ao caso HSBC ou à operação Zelotes.

As onze reportagens sobre o caso Lava-Jato reforçam constantemente o envolvimento dos servidores públicos e, principalmente, do Partido dos Trabalhadores (PT), evocando, em todas as reportagens, especificamente os nomes de Lula e Dilma. As referências a José Dirceu, ao tesoureiro do PT, João Vaccari e ao "Mensalão" também são frequentes. Várias reportagens trazem o uso de diversas vozes intercaladas (jornalista-narrador; empreiteiro; advogado; juiz e outras fontes não citadas) de modo a tentar obliterar as afirmações sem referência de quem as proferiu ou de onde exatamente foram retiradas, deixando o texto ambíguo e repleto de afirmações "sem autor", produzidas, contudo, pela revista. São também recorrentes frases assertivas ao longo das reportagens - tais como "o escândalo de corrupção da Petrobras já é, de longe, o maior de todos os tempos" (RANGEL, Rodrigo, Veja, edição 2416, p.48) quando, quase concomitantemente, vinha a público o caso Zelotes, cujo desfalque nos cofres públicos causados em grande parte por entes privados foi estimado em 19 bilhões, maior que a estimativa do Lava-Jato. Isto, justamente com a presença ostensiva do caso Lava Jato nas edições da revista em comparação com o significativo silenciamento em relação aos outros casos de corrupção que vieram a público, constroem o caso de modo a caracterizar uma hipérbole.

A operação "Lava-Jato" (nome dado ao caso pela Polícia Federal) é chamada constantemente de "Petrolão". O enunciador funde o nome da Petrobras - uma das 
empresas estatais mais antigas do país e, ainda que atualmente seja uma empresa de capital misto, considerada ainda uma dentre as estatais - ao Mensalão, escândalo de corrupção ocorrido ainda no primeiro mandato do presidente Lula, que envolvia o pagamento de uma "mensalidade" aos deputados governistas em troca do voto a favor dos projetos do governo. A prática, ainda que amplamente praticada dentro da política brasileira e por diversos partidos, foi fortemente vinculada à imagem do Partido dos Trabalhadores, tendo causado a condenação e prisão do então ministro da Casa Civil, José Dirceu. O "Petrolão", portanto, é uma apropriação de outros discursos realizada pelo enunciador, mobiliza uma interdiscursividade ou memória discursiva, de novo a criar significados: enfatiza a corrupção vinculada ao ente público, à empresa estatal, ao Estado juntamente com o Partido dos Trabalhadores. Não há no termo "Petrolão" nenhuma referência clara à organização das empreiteiras privadas de modo a constituir um cartel e superfaturar os contratos prestados à Petrobras. O uso recorrente do termo opera um reforço contínuo para acionar a memória discursiva do mensalão, e, assim, construir o PT como o partido corrupto e o grande responsável pelo caso de corrupção dentro da Petrobras:

[...] as agruras do PT com o petrolão são fruto do mesmo pecado original que produziu o escândalo do mensalão: a ideia assombrosa de que o partido pode se servir do Estado como se fosse sua propriedade, das leis como se existissem apenas para os outros e das instituições como bombeiros de suas eternas crises (PEREIRA, D.; BONIN, R. Veja, edição 2414, p. 47).

É recorrente também recurso à metáfora dentro das reportagens: "bolsos dos políticos"; "tempos de bonança"; "amizades nascidas no poder valem pouco atrás das grades". Na frase "Não se sabe o que esses bolsos que conheceram o dinheiro da UTC podem fazer por Pessoa agora - a não ser morrer politicamente de braços dados com ele" (PEREIRA, D.; BONIN, R. Veja, edição 2414, p.42), o termo "PT" é substituído por "bolsos". Já na conclusão da reportagem, mobiliza-se novamente o interdiscurso do mensalão de modo a fazer da "estrela" do "PT", a qual significava a "esperança" numa nova política, significar a "corrupção" através da menção à "cueca": 
[...] na semana passada o PT ainda teve coragem de comemorar seus 35 anos de fundação com aplausos a Vaccari e o lider-mor do partido não se constrangeu em defendê-lo. A estrela que já simbolizou a esperança dos brasileiros em tempos mais republicanos na política, cedeu lugar à mochila, à cueca e a tudo aquilo que guarde dinheiro sujo (PEREIRA, D.; BONIN, R. Veja, edição 2414, p. 53).

$\mathrm{Na}$ edição 2411, de 4 de fevereiro, a reportagem de capa mescla a voz do jornalista com trechos de falas de Léo Pires, diretor da empreiteira OAS (envolvida no caso Lava-Jato). Em uma delas, Léo Pires diz: "Vocês acham que eu ia atrás desses caras [os políticos] para oferecer grana a eles?” (p. 41 - grifo nosso). A presença desta fala, logo no início da matéria, nos ajuda a compreender como se constrói a figura dos empreiteiros: a iniciativa, a "cabeça" do esquema e, logo, "o corrupto por excelência" não seriam eles, indicando uma visão dual entre os políticos como essencialmente corruptos e os empresários como sujeitos passivos (SOUZA, 2009).

Sendo os primeiros atingidos pelas investigações da PF e tendo sido alguns dos diretores e donos das construtoras presos durante o processo, os empreiteiros têm sua figura construída de tal modo a minorar suas responsabilidades no caso. Assim, o empreiteiro preso é quase como um mártir, o corpo de um indivíduo condenado e responsabilizado além do que deveria, abandonado pelos "cabeças" ou os responsáveis (e corruptos) "reais":

Antes dono de um porte imponente e até ameaçador, Pessoa [um dos empreiteiros presos] está magro e abatido. As acusações de corrupção ativa, lavagem de dinheiro e participação em organização criminosa que pesam sobre ele poderiam ser atenuadas caso pudesse contar em delação premiada, quem na hierarquia política do país foi ora sócio, ora mentor dos avanços sobre os cofres da Petrobras (PEREIRA, D.; BONIN, R. Veja, edição 2414, p. 40 - grifo nosso).

A referência ao corpo é mobilizada como descrição do sofrimento do empreiteiro, um indivíduo antes saudável que agora está doente e sofre com os constrangimentos, com o peso que se faz sobre ele. O peso não vem de si mesmo, não é auto-infligido ou consequência de seus atos, mas vem especificamente de "acusações" (de corrupção) que, em última instância, seriam "concretamente" de responsabilidade dos atores da estrutura - política - do país. É o peso da estrutura e da hierarquia política do país que, 
em última instância, comprime o indivíduo, que o faz sofrer, que o faz doente, que o faz corrupto.

Mas se a estrutura política que pesa sobre o corpo do indivíduo empreiteiro tem uma hierarquia é porque tem um cabeça, um chefe que só pode ser político. O PT e, mais especificamente, Lula e Dilma, são os nomes que aparecem em todas as 11 reportagens. Eles são os únicos supostos “suspeitos” cujas vozes não aparecem ao longo das reportagens para comentar as acusações. Existem, para a revista, responsáveis pela corrupção, e, ainda que não condenados pela justiça ou indicados pelos delatores, é certo, para a Veja, que são os governantes do PT, Lula e Dilma.

Assim, os efeitos de sentidos que emergem das 11 reportagens constroem uma estrutura política brasileira hierárquica e autonomizada das relações sociais e econômicas presentes no país, que remete às ideias do culturalismo criticado por Jessé Souza, onde o Estado é o ente corrupto e o personalismo impera. É a estrutura política e pública que emerge dos governos do PT que se projeta sobre os indivíduos e produz a corrupção no país. Ela controla a tudo e a todos, corrompe os indivíduos da iniciativa privada e escapa da condenação que se faz sobre estes. A corrupção no Brasil tem uma origem e direção: emana do Estado, da estrutura hierárquica da política corrompida pelo agente da corrupção, o PT.

Só resta à Veja torcer pela "delação premiada" e assim ela o faz ao longo das 11 reportagens. A delação teria o poder de redimir os indivíduos corrompidos e salvar o país da crise política que desestabilizaria a economia, pois, necessariamente, a delação apontará para o governo do PT, para Lula e Dilma, condenando-os. Somente a salvação/condenação da figura da delação - a qual redime o indivíduo e condena a estrutura política do governo petista; redime o agente privado e condena o agente público - que soluciona a corrupção no Brasil.

A única reportagem de capa que não aborda o caso Lava-Jato fala sobre o caso da FIFA. É notório que, enquanto os casos de corrupção da Lava-Jato estavam sempre citados dentro da área da revista referentes a assuntos do "Brasil", a reportagem da FIFA se localizava na seção "Geral", criando um efeito de distanciamento do caso em relação aos(às) brasileiros(as), apesar de existirem vários brasileiros envolvidos no processo. Tal efeito de distanciamento, obra do enunciador, permite que ele aborde a corrupção de forma diferente que no caso Lava-Jato. Não se comenta acerca de uma 
possível delação premiada, não se deriva a corrupção de um grupo, mas mobiliza-se outra voz, a da procuradora estadunidense, para indicar que a corrupção seria algo historicamente presente na FIFA. Ao mesmo tempo, constrói o efeito de que este caso de corrupção seria algo menor, menos importante a partir de dois enunciados. $\mathrm{O}$ primeiro enunciado faz referência à especificidade da lei estadunidense que não levaria em consideração se o dinheiro referente à corrupção era público ou privado:

É indiferente, do ponto de vista da legislação americana, se a corrupção envolve dinheiro privado (como ocorre majoritariamente nas estripulias da FIFA) ou público (ao modo do que a documentação americana diz ter acontecido na África do Sul). O crime é de mesmo teor. Uma empresa obter vantagem mesmo sem lesar o contribuinte equivale a desequilibrar a livre concorrência (LEITÃO, L.; GASPAR, M.; SALVADOR, A. Veja, edição 2428, p. 72).

É interessante notar a escolha léxica do enunciador: "estripulias". Quem faz estripulias? Crianças em brincadeiras, coisas sem uma grande importância.

Já o segundo enunciado pergunta retoricamente se a corrupção no futebol seria um tema importante, argumentando em seguida que sim, seria, e que a Veja trataria coisas sérias de forma séria. Apesar desse argumento, os efeitos de sentido que emergem da reportagem não são predominantemente estes, de modo que a própria existência da pergunta indica que "o leitor" não acharia o caso tão sério. A corrupção quando entre agentes privados é construída, portanto, como uma "estripulia", distanciada dos(das) brasileiros(as), tendo pouca importância concreta na vida destes(as). Contudo, além do envolvimento de brasileiros no caso, incluindo a TV TEM, afiliada da Rede Globo, sabe-se que o futebol mobiliza uma quantia considerável de dinheiro, ocupa um lugar central na cultura e identidade brasileira e, por isso mesmo, pode ser um poderoso meio de mobilizar o imaginário e a opinião pública no país. Percebe-se que, mesmo em casos de corrupção entre entes privados, é possível estabelecer relação destes casos com o ente público.

\section{Para continuar o debate}


Esse artigo buscou compreender os efeitos de sentido que emergem da cobertura da revista Veja acerca dos casos de corrupção no Brasil e como esta constrói um conceito de corrupção. A partir da análise das 12 reportagens de capa analisadas bem como da leitura das 25 edições da revista, evidenciou-se a cobertura desigual e tendenciosa acerca dos quatro maiores casos recentes de corrupção no país, existindo um enorme destaque para a Lava-Jato em detrimento da cobertura de casos igualmente escandalosos e onerosos ao erário, como HSBC e Zelotes. Estes três casos diferem-se não pelo volume de dinheiro que desfalcaram do tesouro nacional, mas pela maior ou menor participação de agentes público e de políticos vinculados ao PT. A cobertura da Lava-jato tem como sentido principal a culpabilização espantalhesca do PT ao invés de tentar cobrir o caso de forma objetiva e séria.

A ampla divulgação do caso Lava-Jato, assim como a maneira de se enunciar acerca dele, realizava um esforço sistemático de construção da esfera política e pública como os locais da corrupção. Esta aparece como algo que emana e que tem apenas um sentido e fonte de origem específica: o Partido dos Trabalhadores, personificado em seus mais famosos membros, o ex-presidente Lula e a então presidenta Dilma. Sendo assim, a corrupção pode ser solucionada, desde que suas fontes sejam "delatadas" e, assim, desempossadas da política.

A personificação e redução do fenômeno da corrupção como atuação e produção de um único partido da esfera pública e política contribui para aumentar o sentimento de indignação de parte da população, a qual pedia o impeachment de Dilma e a prisão de Lula como se fossem as soluções de todos os males dos(as) brasileiros(as). Enquanto revista de maior circulação no Brasil, a cobertura parcial, desonesta e irresponsável da Veja acerca do tema da corrupção atua de maneira contrária ao debate público sério e, se retomarmos as condições de produção da enunciação destas reportagens, percebe-se que os sentido produzidos pela revista vão ao encontro dos sentidos presentes no imaginário das pessoas que praticavam violências contra membros do governo Dilma e xenofobia contra os(as) nordestinos(as) após a reeleição da presidenta Dilma e ao longo do primeiro semestre de 2015. Muito pior do que não contribuir ao debate público, os sentidos das reportagens contribuíam para alimentar a irracionalidade violenta.

A noção de corrupção mobilizada pela Veja se alinha com o senso-comum que tem base no "culturalismo" criticado por Jessé Souza (2009), ou seja tem base nas 
compreensões patrimonialistas e personalistas dominantes acerca do Brasil e de problemas como a corrupção, que é vista como tendo origem no estado corrupto, em contraposição ao virtuoso mercado (SOUZA, 2009, p. 117-118). Dentro do Estado corrupto o PT seria o agente corruptor e Lula e Dilma seriam as cabeças da corrupção, demarcando a visão ainda restrita e personalista adotada pela Veja em relação ao tema. Assim se desconsideram totalmente aspectos relevantes de uma análise complexa e crítica da sociedade, como a estrutura democrática e a articulação da estrutura política brasileira e dos grandes empresários na formação do projeto dominante do país e suas características de extrema desigualdade. Neste sentido, seria interessante se analisar como, após o processo de afastamento de Dilma Roussef da presidência do Brasil em 2016, a revista continuaria a tratar da corrupção do Estado.

Considera-se relevante retomar importantes formulações de Céli Pinto (2011) a respeito da corrupção, de modo a apresentar novas perguntas e provocações sobre o tema. Conforme Pinto afirma, a corrupção seria um "fenômeno de grandes proporções que atinge toda a sociedade" (2011, p. 51), logo, não emana de um lugar - da política. A corrupção no Brasil perpassa toda a sociedade em suas diferentes esferas e seu funcionamento se daria a partir de uma

[...] legitimidade da hierarquia das desigualdades, modo como se constitui a sociedade brasileira, onde cada indivíduo se identifica em uma escala hierárquica, na qual o princípio da igualdade é substituído por quantidade de poder de natureza diversa. Essa escala abrange desde os que detêm poderes políticos e econômicos até aqueles que detêm como poder o fato de serem homens, ou de serem brancos ou de terem emprego, entre outros. Em síntese, uma sociedade em que pessoas sentem-se com direitos diferenciados, o que constitui a antítese da cidadania. Esse é um caldo de cultura muito particular para o exercício da corrupção e atos ilícitos agregados (PINTO, 2011, p. $54)$.

Assim, pessoas comuns, ocupando posições diversas dentro dessa hierarquia das desigualdades, cada uma com seus pequenos privilégios e poderes, podem ser corruptas, assim como os políticos e empreiteiros da Lava-Jato, os dirigentes da FIFA, os clientes do HSBC e as empresas sonegadoras de impostos da Operação Zelotes. Não existe uma autonomização da constituição dos sujeitos políticos em relação aos sujeitos eleitores: nós, eleitores, somos feitos do mesmo material simbólico cultural que nossos 
representantes. A sociedade civil e a iniciativa privada podem ser tão corruptas quanto o Estado e seus governantes, sendo que tanto as instituições do Estado e do mercado possuem características ambíguas, porém compreendidas dentro da lógica de dominação do capitalismo brasileiro e suas características de extrema desigualdade.

Trazer o tema da corrupção para o debate público brasileiro mobilizando pesquisas, conceitos e teorias sociais, os quais ajudam a compreender o fenômeno de modo mais criterioso e sério, é responsabilidade de todos aqueles e aquelas que desejam compreender o fenômeno efetivamente. A responsabilidade é ainda maior para aqueles(as) que se formam nas Ciências Humanas e Sociais. Este artigo, dentro das suas possibilidades e limitações, buscou contribuir para isto.

Finalizamos com uma provocação que suscita outro importante debate acerca da corrupção no Brasil. Maria Lucia Fattorelli, ex-auditora da dívida cidadã defende que o enfoque exagerado na corrupção vinculada ao governo como o causador dos problemas do(da) brasileiro(a) pode atuar de maneira a esconder outras discussões relevantes, tal como a do sistema econômico adotado em nosso país e o sistema da dívida pública brasileira como questões que afetam substancialmente os problemas nacionais (AUDITORIA CIDADÃ DA DÍVIDA, 2015).

Fattorelli afirma também, em entrevista dada a Carta Capital (TRUFFI, 2015), que a dívida pública em si, como um sistema legalizado, seria um "mega esquema de corrupção institucionalizado", considerando-se que nesse processo quase metade do PIB brasileiro seria utilizado como pagamento para a iniciativa privada, na figura do capital financeiro privado, sem nenhuma contrapartida para o bem público. Seria um tipo de corrupção público-privada, numa dimensão gigantesca que, segundo reportagem de $\mathrm{O}$ Globo, atingiria o valor de 2, 5 trilhões de reais ${ }^{17}$, os quais seriam pagos como juros e amortização da dívida dentro de um sistema legalizado.

Retomando Céli Pinto, podemos compreender a corrupção como “[...] essencialmente, a apropriação do público por interesses privados [...]” (PINTO, 2011, p. 51) e, assim, pode-se entender o sistema da dívida pública, como apontado pela exauditora da dívida cidadã, como uma forma de corrupção institucionalizada e legalizada, porém muito pouco ou não trabalhada na grande mídia.

\footnotetext{
${ }^{17}$ Informações disponíveis em: <http://g1.globo.com/economia/noticia/2015/07/divida-publica-sobe-35em-junho-para-r-25-trilhoes.html>.
} 


\section{Referências}

AGÊNCIA SENADO. CPI do HSBC. 2015. Disponível em: <http://www12.senado.leg.br/noticias/senado-agora/2015/03/24/cpi-do-hsbc> Acesso em 23/07/2015.

ARAUJO, Bruno; JORGE, Thais. Discurso jornalístico e corrupção política: a construção de uma cobertura legalista e personificada em Veja e Carta Capital. Verso e Reverso, XXIX(70):2-13, janeiro-abril 2015.

AUDITORIA CIDADÃ DA DÍVIDA. A Corrupção e o Sistema da Dívida - 2015 (vídeo-aula). Postado em 24 de abril de 2015. Disponível em: $<$ https://www.youtube.com/watch?t=82\&v=rRQHG5kd-Q0> Acesso em: 26 de junho de 2015.

BONIN, R. Os favores do empreiteiro. Veja, São Paulo, edição 2423, p. 50-57, 29 de abril de 2015. Disponível em: <http://veja.abril.com.br/acervodigital/home.aspx> Acesso em 23 de julho de 2015.

CARTA CAPITAL. Zelotes: Gerdau e RBS, afiliada da Globo, são principais alvos, diz jornal. Publicado em 31 de março de 2015. Disponível em: $<$ http://www.cartacapital.com.br/blogs/parlatorio/zelotes-gerdau-e-rbs-afiliada-daglobo-sao-principais-alvos-diz-jornal-7182.html> Acesso em 22/07/2015.

CRUZ, D. Dívida pública sobe 3,5\% em junho, para R\$ 2,5 trilhões. Portal G1, $\begin{array}{llllll}\text { publicado em } & 27 & \text { de } & \text { julho de } & 2015 . & \text { Disponível }\end{array}$ em:<http://g1.globo.com/economia/noticia/2015/07/divida-publica-sobe-35-em-junhopara-r-25-trilhoes.html> Acesso em 27/07/2015.

COUTINHO, L; PAULIN, I; MEDEIROS, J. de. A farra da antropologia oportunista. Veja, São Paulo, edição 2163, p. 154-161, 5 de Maio de 2001 . Disponível em: $<$ http://veja.abril.com.br/acervodigital/home.aspx> Acesso em 23 de julho de 2015 GASPAR, M.; SAKATE, M. “Onde há fumaça...”. Veja, São Paulo, edição 2415, p. 4047, 4 de Março de 2015. Disponível em: $<$ http://veja.abril.com.br/acervodigital/home.aspx> Acesso em 23 de julho de 2015. GIBSON O.; GAYLE, D. FIFA officials arrested on corruption charges as World Cup inquiry launched. The Guardian Publicado em 27 de maio de 2015. Disponível em 
<http://www.theguardian.com/football/2015/may/27/several-top-fifa-officials-arrested> Acesso em: 23/07/2015.

INTERNATIONAL CONSORTIUM OF INVESTIGATIVE JOURNALISTS. Swiss Leaks: Murky cash sheltered by bank secrecy. Disponível em: $<$ http://www.icij.org/project/swiss-leaks> Acesso em 22/07/2015

LEITÃO, L.; GASPAR, M.; SALVADOR, A. Corrupção Padrão FIFA. Veja, São Paulo, edição 2428, p. 68-77, 3 de junho de 2015. Disponível em: <http://veja.abril.com.br/acervodigital/home.aspx> Acesso em 23 de julho de 2015.

MINISTÉRIO PÚBLICO FEDERAL. Operação Lava Jato. 2015. Disponível em: <lavajato.mpf.mp.br> Acessoem: 19 de julho de 2015.

NERY, N.; MASCARENHAS, G. 12 empresas negociaram propina no Carf, diz PF. Folha de S. Paulo Publicado em 31 de março de 2015. Disponível em: <http://www1.folha.uol.com.br/mercado/2015/03/1610495-12-empresas-negociarampropina-no-carf-diz-pf.shtml>Acesso em: 23/07/2015.

ORLANDI, Eni P. Análise de Discurso: Princípios e Procedimentos. Campinas: Pontes, 2013.

PEREIRA, D.; BONIN, R. O Homem da Mochila. Veja, São Paulo, edição 2412, p. 46 - 53, 11 de fevereiro de 2015. Disponível em: $<$ http://veja.abril.com.br/acervodigital/home.aspx> Acesso em 23 de julho de 2015. PEREIRA, D.; BONIN, R. "O chefe da polícia pelo telefone mandou avisar...". Veja, São Paulo, edição 2413, p.40 - 49. 18 de Fevereiro de 2015. Disponível em: <http://veja.abril.com.br/acervodigital/home.aspx> Acesso em 23 de julho de 2015. PEREIRA, D.; BONIN, R. O que ele sabe é pura dinamite. Veja, São Paulo, edição 2414, p.38-47, 25 de fevereiro de 2015. Disponível em: <http://veja.abril.com.br/acervodigital/home.aspx> Acesso em 05 de março de 2016. PEREIRA, D.; BONIN, R.; MARQUES, H. O homem dos Presidentes. Veja, São Paulo, edição 2422, p. 48-55, 22 de abril de 2015. Disponível em: $<$ http://veja.abril.com.br/acervodigital/home.aspx> Acesso em 05 de março de 2016. PEREIRA, D.; RANGEL, R.; BONIN, R. O Juiz e o juízo final. Veja, São Paulo, edição 2424, p.40-47, 6 de maio de 2015. Disponível em: $<$ http://veja.abril.com.br/acervodigital/home.aspx> Acesso em 23 de julho de 2015. 
PETROBRAS. Composição de Capital Social, 2015. Disponível em: $<$ http://www.investidorpetrobras.com.br/pt/governanca-corporativa/capital-social> Acesso em 05 de março de 2016.

PORTAL G1. Caso FIFA: perguntas e respostas. Publicado em 28 de maio de 2015. Disponível em: <http://g1.globo.com/mundo/noticia/2015/05/entenda-acusacoes-decorrupcao-fifa.html> Acesso em: 23/07 de 2015.

PINTO, Céli Regina Jardim. Os Nomes da Corrupção In A banalidade da corrupção: uma forma de governar o Brasil. Belo Horizonte: Editora UFMG, 2011.

RANGEL, R.; MARQUES, H. Sabotagem ou negligência. Veja, São Paulo, edição 2426, p. 46-53, 20 de maio de 2015. Disponível em: <http://veja.abril.com.br/acervodigital/home.aspx> Acesso em 05 de março de 2016.

RANGEL, R. Os nomes sobre Suspeita. Veja, São Paulo, edição 2416, p. 48-53, 11 de março de 2015. Disponível em: <http://veja.abril.com.br/acervodigital/home.aspx> Acesso em 05 de março de 2016.

RANGEL, R.; PEREIRA, D.; BONIN, R. O penúltimo degrau. Veja, São Paulo, edição 2431, p. 46-53, 24 de junho de 2015. Disponível em: $<$ http://veja.abril.com.br/acervodigital/home.aspx> Acesso em 23 de julho de 2015.

RANGEL, R.; BONIN, R.; MEGALE, B. Petrolão - Os empreiteros envolvidos ameaçam Lula e Dilma. Veja, São Paulo, edição 2411, p. 41 - 47, 4 de fevereiro de 2015. Disponível em: <http://veja.abril.com.br/acervodigital/home.aspx> Acesso em 05 de março de 2016.

RIBEIRO, E. Relações perigosas em Veja. Observatório da Imprensa. Publicado em $18 / 11 / 2001$. Disponível

em: <http://www.observatoriodaimprensa.com.br/artigos/asp2111200197.htm > Acesso em 05 de março de 2016.

RODRIGUEZ, D. A. Entenda o caso dos vazamentos do HSBC. Carta capital. Publicado em 22/02/2015. Disponível em: $<$ http://www.cartacapital.com.br/economia/entenda-o-caso-dos-vazamentos-do-hsbc7392.html> Acesso em 05 de março de 2016.

SCHREIBER, M. Operação Zelotes: Alvo de escândalo bilionário de corrupção, o Carf deveria ser extinto? BBC Brasil. Publicado em 15 de abril de 2015. Disponível em: 
<http://www.bbc.com/portuguese/noticias/2015/04/150414_carf_corrupcao_ms_rb> Acesso em 05 de março de 2016.

SOUZA, Jessé et al. A ralé brasileira: quem é e como vive. Editora UFMG, 2009.

SOUZA, Pedro de. Análise do discurso. Florianópolis: LLV/CCE/UFSC, 2011.

TRUFFI, R. Entrevista - Maria Lucia Fattorelli - "A dívida pública é um mega esquema de corrupção institucionalizado". Carta Capital. Publicado em 9 de junho de 2015. Disponível em: <http://www.cartacapital.com.br/economia/201ca-divida-publica-e-ummega-esquema-de-corrupcao-institucionalizado201d-9552.html> Acesso em 05 de março de 2016.

UNITED STATES DEPARTMENT OF JUSTICE. Nine FIFA Officials and Five Corporate Executives Indicted for Racketeering Conspiracy and Corruption. Publicado em 27 de maio de 2015. Disponível em: <http://www.justice.gov/opa/pr/nine-fifaofficials-and-five-corporate-executives-indicted-racketeering-conspiracy-and> Acesso em 05 de março de 2016.

Recebido em 07 de março de 2016.

Aprovado em 31 de agosto de 2016. 